\title{
La impatía como aprehensión de las vivencias del otro. Análisis fenomenológico de la experiencia impática*
}

\author{
Pedro Juan Aristizábal Hoyos \\ Universidad Tecnológica de Pereira
}

Recibido: septiembre 8 de 2009 - Aprobado: noviembre 4 de 2009

R

Resumen

El presente texto hace un análisis de la impatía (Einfühlung) como una experiencia que expresa la esencia propia de las relaciones intersubjetivas. En primera instancia, se muestra en qué consiste el darse intuitivo de la conciencia extraña a partir de mi propio flujo de conciencia. En segundo lugar, se delimita la esencia del acto impático estableciendo la comparación (como variación imaginativa) con otros tipos de actos de presentificación. Al final ponemos ante los ojos algunas características del cuerpo vivo extraño como ámbito propio de lo psicofísico.

Palabras clave: Husserl, impatía, cuerpo vivo.

Este artículo se publicó en el Anuario Colombiano de Fenomenología, III. Instituto de Filosofía. Universidad de Antioquia, 2009.

* Profesor de la Universidad Tecnológica de Pereira. Miembro de la Sociedad Colombiana de Filosofía. Miembro ordinario del Círculo Latinoamericano de Fenomenología (CLAFEN). Correo electrónico: juancelibur@ hotmail.com 


\section{Empathy as aprehension of others experiences. Phenomenological analysis of the empathic experience}

\section{Abstract}

The up-to-date text makes an análisis of the empathy, (Einfhülung), as an experience that expresses the own essence of intersubjective relation-schips. At first it is shown in what consists the intuitive giving of strange conscionsness starting from my own flow of conscionsness. In the second place is limited by the essence of the empatick act establishing the comparison (as imaginative variation) with other kinds of presentiating acts. At the end we put in front of the eyes some characteristics of the strange living body as the own boundary line of the psychophysical.

Key words: Husserl, Empathy, Living body. 


\section{L'empathie comme appréhension des "expériences" de l'autre. Analyse phénoménologique de l'expérience empathique}

\section{Résumé}

Ce texte analyse l'empathie (Einfühlung) comme une expérience qui exprime I'essence propre des relations inrsubjective. D'abord on montre ce que signifie" se donner intuitivement de la conscience étrange à partir de mon progre flux de conscience. Ensuite on essaie de limiter l'essence de l'acte empathique tout en établissant une comparaison (comme variation imaginative) avec d'autres acte de presentation. Enfin nous présentons quelques caractéristiques $\mathrm{d}$ corps vivant et étrange comme un domaine progre du psycophysique.

Mots clés: Husserl, empathie, corps vivant. 
Esta investigación sobre la impatía requiere el acompañamiento del trabajo doctoral de Edith Stein (2004), dirigido por Husserl, dedicado a explicitar el tema central de la intersubjetividad ${ }^{1}$. La impatía ${ }^{2}$ se conoce en general como la teoría de la experiencia del otro o de la aprehensión de sus vivencias, por contraposición a la experiencia que la conciencia hace de sí misma. Dicha experiencia consiste en sentir en el fluir de la propia conciencia otra semejante, o mejor, es la experiencia de la vida psíquica extraña, de lo dado en el vivenciar del otro $y$, en consecuencia, sabemos de ese vivenciar porque se alcanza directamente, en legítima intuición fenomenológica -y por tanto, no inferida- el objeto del acto experiencial.

1 Los textos de Husserl sobre la impatía, explícitos a partir de los años treinta, no representan para el filósofo ningún descubrimiento. Esa problemática ya se hace palpable quince años antes desde su época de enseñanza en Gotinga. Sus reflexiones inspiraron precisamente a Edith Stein para desarrollar el tema. Esto tiene la consecuencia importante de que las investigaciones sobre la intersubjetividad no son tardías en Husserl, pues era algo que estaba ya inédito en Ideas II.

2 La traducción de Einfühlung por "impatía" y no por "empatía" se hace siguiendo los lineamientos trazados por el Glosario-guía para traducir a Husserl, que dirige y organiza Antonio Zirión de la UNAM (disponible en http://www.filosoficas.unam.mx/gth/gthii/htm), pues el significado de "empatía" tiene una fuerte repercusión afectiva, y no es con ese sentido especial como lo refiere Husserl. El concepto alemán Einfühlung como lo utiliza el filósofo se aplica más directamente a los actos y experiencias objetivantes. Estos últimos, como se sabe, son explicitados por el autor desde sus Logische Untersuchungen en discusión con Brentano (Cf., Brentano, 1935, p. 110 ss.).

Mientras Brentano establece un limitado tipo de fenómenos o actos psíquicos (representaciones, juicios y sentimientos, de los cuales sólo los dos primeros son objetivantes), para Husserl el número posible de "estructuras intencionales" (o actos psíquicos) es ilimitado y, en consecuencia, también el de los actos objetivantes. Los actos objetivantes son, en general, aquellos actos que hacen presente el objeto por sí mismo, o bien, que se fundan sobre otros actos que son objetivantes. Estos actos se presentan como experiencias definidamente intencionales dirigidas a determinados objetos y, por tanto, son vivencias que requieren ser representadas, en contraposición a los sentimientos en general y a otros tipos de actos que son actos no objetivantes o de intención secundaria (Cf., Husserl, 1982, §15, p. 508 ss., y § 37).

Entonces, en su ámbito específico intersubjetivo, la "impatía" (Einfühlung) se refiere a aquellas operaciones efectivamente objetivantes con las que el sujeto trascendental constituye el sentido otro trascendental u otro en sentido mundanal, como lo veremos a lo largo de este texto. Para una ampliación del concepto de "impatía", véase igualmente la nota al pie de la traducción que hace Julia Iribarne del texto No. 38 de Husserl, "Zeitigung - Monade" (Iribarne, 2005, p. 315). En uno de los tomos sobre Fenomenología de la intersubjetividad, Husserl delimita dos modalidades de impatía de la siguiente manera: "Die uneigentliche Einfühlung ist die passiv assoziative Indizierung einer fremden Subjectivität, die eigentliche. <Einfühlung> das aktive Mittun und Mitleiden, sich ichlich Motivieren- lassen, aber auch im Untergrund den inneren Motivationen Nachgehen statt den Assoziationen (...)" 1973, p. 455, nota). "La impatía impropia es la indicación pasiva asociativa de una subjetividad extraña, la <impatía> propia, el co-hacer activo y co-padecer, dejarse motivar yoicamente, pero también en el fondo el seguir las motivaciones internas en lugar de las asociaciones (...)" (Cf., Iribarne, 1988, p. 38). Con estas modalidades, Husserl da a entender que la impatía propia apunta a una operación efectivamente objetivante del sujeto trascendental, mientras la impatía impropia es meramente pasiva y asociativa y de ese modo se experimenta la subjetividad extraña. Así, mientras una es pasiva y comprensiva, la otra es activa y reflexiva y por tanto, más vinculada al ámbito esencialmente científico de la fenomenología. 
Aunque Husserl, en Erste philosophie, consideró que el concepto era insuficiente para dar cuenta de la experiencia trascendental del otro, no encontró de todas maneras un término más adecuado como núcleo central que explicitara exhaustivamente el problema de la intersubjetividad (Husserl, 1987, Lección 35; Márquez, 1897, pp. 131-158, nota) ${ }^{3}$.

\section{La esencia de la experiencia impática (preámbulo)}

En la discusión sobre el tema de la impatía hay una suposición no explícita: "nos están dados sujetos ajenos y sus vivencias" (Stein, 2004, p. 19). De este modo, la impatía, en cabal modo fenomenológico, es un darse intuitivamente una conciencia extraña a partir de mi propio flujo de conciencia. El objetivo de la fenomenología, en este sentido, es indagar su esencia, su modo de darse, y lo que designa el concepto para abarcar esa experiencia tan fundamental por la cual tenemos noticias de cómo experimentamos al otro y sus relaciones.

En estricto análisis fenomenológico, para delimitar el significado de la experiencia impática, es preciso establecer la comparación (como variación imaginativa) con otros tipos de actos con el fin de poner ante los ojos la singularidad de esa experiencia. ¿Cómo mostrar la esencia del acto impático? Alguien viene y me cuenta el dolor que le ha producido la muerte de su padre y yo capto ese dolor a partir de ciertas manifestaciones como su semblante conmovido; por ejemplo, la torsión de su rostro y la agitación lenta de sus manos cubriéndolo. Yo entonces capto su dolor. ¿Qué es ese captar, ese notar el dolor? Para nuestro análisis eidético, no importa en principio cómo he llegado a captar el dolor de ese otro que llega, sino el captar ese sí mismo, es decir, ¿qué es eso que se da a mi experiencia como dolor no mío?

Stein se propone responder al interrogante estableciendo la diferencia entre percepción externa e impatía. A pesar de que el dolor del otro tiene manifestaciones externas, por ejemplo, los cambios de su rostro, yo no tengo, en estricto modo, percepción externa de él. ¿Qué significa esto? Pues que

3 Especificando, la impatía (Einfühlung) se puede comprender como aquella operación de la conciencia que supone un "tipo de reflexión cuyos objetos son las otras mentes" (Cf. Embree, 2003, p. 41). 
no es una realidad que se presenta y se vivencia como tantas otras, en su manifestación espacio-temporal, como un objeto cualquiera del mundo.

En consecuencia, todo objeto del mundo espacio-temporal, aunque sea nombrado y captado completamente por motivos inmanentes, sólo se exhibe a la conciencia perceptiva por medio de matices o escorzos (Husserl, 1986, p. 93) con sus horizontes espacio-temporales dados (sean estos internos y externos o de retención y protención). Sabemos igualmente que cualquier indagación fenomenológica de la percepción no se acaba en la percepción particular; ella investiga el significado general de percepción, su esencia, y obtiene el saber de su singularidad en pura abstracción eidética.

Visto así, ¿qué tipo de realidad es entonces la impatía? Puesto que "el mundo en el que vivo no es sólo un mundo de cuerpos físicos, además de mí, también hay en él sujetos con vivencias, y yo sé de ese vivenciar" (Stein, 2004, p. 21). Aunque pueda engañarme con respecto al conocimiento del otro, se presentan fenómenos de la vida psíquica en que el extraño está ahí de modo indubitable. Éste no se exhibe como cuerpo físico (Körper), sino como Leib, como cuerpo vivo que se orienta desde dentro de sí mismo: "cuerpo vivo sentiente al que pertenece un yo (...) que siente, padece, quiere, y cuyo cuerpo vivo no está incorporado a mi mundo /fenoménico/ (...) sino que es centro de orientación de semejante mundo fenomenal" (Stein, 2004, p. 21).

Hasta ahora hemos visto que los actos de impatía difieren de los actos de percepción externa en tanto que son fenómenos psíquicos a los que les conviene un cuerpo vivo que se orienta intencionalmente a partir de sí, que pone el mundo a su alrededor en tanto es centro y, por último, diríamos que no es posible lograr una perspectiva en la que se pueda tener acceso originariamente al dolor mismo.

Respecto a este último punto, el resultado de querer abordar el dolor por sus manifestaciones externas es sumamente vago; me daría cuenta de que, aunque de un solo golpe se perciba su entidad misma, este objeto de experiencia externa se me da por perfiles con la parte percibida vuelta hacia mí, y pudiera contemplarlo por los lados que quisiera, pero no habría ningún avance notorio, en tanto no tengo acceso a la orientación de su dolor, que, en efecto, se presenta de modo propio y no originario en su vivenciar mismo. 
Mientras el dolor se agota en su darse, los objetos que se presentan a la percepción sensible por medio de matices o escorzos se presentan para Husserl siempre de manera inadecuada por la ausencia de límites inherentes a dicha percepción (Husserl, 1986, p. 99). Por eso afirma:

No hay ninguna percepción de la cosa que sea definitivamente cerrada, siempre queda espacio para nuevas percepciones que determinen con más precisión lo indeterminado y llenen lo no-lleno todavía. Con cada paso hacia adelante se enriquece el contenido de determinaciones del nóema (p. 358).

Entonces, "si la /i/mpatía no tiene el carácter de percepción externa, (...) / sí/ tiene algo en común con ella: que para ella existe el objeto mismo aquí y ahora" (p. 22). Si el objeto para la impatía está dado aquí y ahora, falta determinar entonces si tiene el mismo carácter originario de los actos y los objetos de percepción externa.

Para determinar la originariedad o no del acto impático, es preciso señalar otros objetos que se dan de manera originaria, aunque no sean de percepción externa; por ejemplo, la ideación por la cual "aprehendemos intuitivamente relaciones esenciales; la intelección, verbigracia, de un axioma geométrico, la captación de un valor (...) /y también/ nuestras propias vivencias tal como vienen a darse en la reflexión" (p. 23).

Si las vivencias originarias son todas las vivencias propias presentes, surge la pregunta: ¿muestra la experiencia impática la originariedad del vivenciar propio? No todas las vivencias se dan originariamente en su presente viviente; por ejemplo, recordar, esperar, fantasear, son experiencias cuyos objetos no están presentes directamente ante mí (intuidos), sino solamente presentificados (hechos de nuevo presentes o re-presentados): “El carácter de la presentificación /tal y como se comprende/ es un momento esencial inmanente a estos actos, no una determinación obtenida de los objetos" (pp. 23-24) .

4 Un ejemplo clásico de esta diferencia en la vivencia, es la forma como se presenta el árbol percibido que es vivido de modo diferente al árbol re-presentado. 


\section{Recuerdo-espera-fantasía-impatía}

Ahora bien, es preciso abordar la pregunta de si es la impatía un acto originario con estos actos que, segun hemos dicho, no tienen carácter originario. Con respecto al recuerdo, por ejemplo, de una noche triste, no es un acto originario en referencia a su contenido; esa noche triste tiene la forma de no estar presente ahí, sino de haber estado viva una vez. El modo de ser originario de estos actos como el recuerdo, la espera, etc., y también la impatía, hacen parte de la llamada presentificación que, en contraposición a lo dado en el presente corporalmente o en persona, se inscriben dentro de otros modos de intuición que son modificaciones o variaciones de la intuición sensible. Así lo expresa Husserl en su más importante obra póstuma Die Krisis: "La percepción es el proto-modus de la intuición: ella representa en protooriginariedad, esto es, en el modus de la mismidad presente" (Husserl, 1991, p. 110, § 28); es presencia en persona. Pero hay otros modos de intuición dados también en persona que son "presentaciones, modificaciones de la presentización; / estas/ hacen conscientes modalidades temporales; por ejemplo, no hacen presente la mismidad-ahí-siendo, sino la mismidad-ahí-habiendo-sido o lo futuro: la mismidad-ahí-que-será" (p. 108).

Entonces, todos estos actos de presentificación en los que se incluye la impatía aparecen como una modificación o una extensión de los actos presentantes protooriginarios. Es decir, los actos presentantes protooriginarios en los cuales hay donación absoluta, percepción presente fenomenológica, se amplían a otros modos de donación, son los actos presentificantes dados también, aunque ya no de manera absoluta e indubitable, pues para las presentificaciones (recuerdo, impatía, espera, etc.) pierde vigencia la donación absoluta e indubitable propia de la percepción fenomenológica originaria, aunque ello no implique que no sean experiencias fenomenológicamente donantes.

Entonces, la espera es de un acto que llegará a ser en persona, por ejemplo, cuando se tiene expectativa frente a un posible reencuentro amoroso; el recuerdo, por ejemplo, de una noche triste que como tal se vivió una vez y no ahora; la imagen fantástica, por ejemplo, de ser el amanuense del maestro 
espiritual Husserl liberándome la carga de dificultad en el trabajo intelectual; alguien querido que viene radiante de alegría al recibir un premio al que aspiraba, y que aprehendo impáticamente en tanto que me transfiero dentro de él, comprendiendo cognitivamente la satisfacción del acontecimiento que, aunque irrelevante para mí, me podría también colmar de alegría.

Todos estos son actos que tienen originalidad en cuanto son presentificaciones, modificaciones de la intuición presente categorial o sensible ciertamente donantes, pero, como hemos dicho, no son originarios en cuanto no tienen su objeto propiamente presente; por ejemplo, el ser del recuerdo o de la espera está en lo recordado o en lo esperado, aunque el acto mismo tiene carácter de posesión: yo en los actos de presentificación.

Miremos, por lo pronto, cómo se manifiesta el yo en estos actos de presentificación (Stein, 2004, pp. 24-25). En el recuerdo, al yo sujeto de dicho acto, le es viable retrospectivamente poner ante los ojos la tristeza pasada, obteniendo la tristeza como objeto intencional y con ella, igualmente su sujeto, el yo de lo acaecido. Entonces, hay igualmente una "doble reducción"; el yo del pretérito y el yo del presente se ponen cara a cara como sujeto y objeto, y a pesar de la mismidad, no hay coincidencia entre ambos y subsiste, pues, la diferencia entre el yo originario que realiza el acto de recordar y el yo no originario recordado; pero asimismo es un tercer yo el que se apercibe de dicha dualidad, tal y como lo refiere Husserl con los niveles de subjetividad implícitos a la disolución o escisión del yo ${ }^{5}$. Por su parte, en la espera hay también distensión temporal pero hacia el futuro, y el sujeto, como yo expectante, construye consciente o inconscientemente el objeto sobre otro tiempo, y en él tiende a revelarse, como imaginariamente, un yo objeto que, por supuesto, no es originario. Y en la fantasía el yo que crea el mundo de la fantasía es originario, mientras el yo que vive en él es no-originario, y en general las vivencias fantásticas frente a otro tipo de vivencias (recordadas-esperadas) se caracterizan porque no se dan como presentificación de vivencias reales, sino como formas no originarias de vivencias presentes.

5 En este sentido, es importante revisar Husserl (1986a, p. 49). Para una ampliación del tema de los tres niveles de subjetividad inherentes a la reducción fenomenológica (y del desdoblamiento del yo en dicha ejecución), revisar Fink (2003, p. 400 ss). . 
Ahora bien, el hecho de que la impatía sea un tipo de presentificación como los otros actos a los que hemos hecho referencia, no significa que no tenga su esencial particularidad. La impatía representa, en consecuencia, un tipo suigeneris de actos experienciales. La diferencia fundamental del fenómeno de la impatía respecto a los actos del recuerdo, la espera y la fantasía de las propias vivencias, se hace notoria cuando nos damos cuenta de que el yo, sujeto de la vivencia impatizada, no es el mismo que ejecuta la impatía, sino el extraño. No ocurre, por ejemplo, como en los actos del recuerdo que están ligados por una conciencia de la mismidad:

[...] mientras vivo aquella/tristeza/ del otro no siento ninguna/tristeza/ originaria, ella no brota viva de mi yo, tampoco tiene el carácter del haber-estado-vivaantes como la /tristeza/ recordada. Pero mucho menos aún es mera fantasía sin vida real, sino que aquel otro sujeto tiene originariedad, aunque yo no vivencio esa originariedad; la /tristeza/ que brota de él es tristeza originaria. En mi vivenciar no originario me siento, en cierto modo, conducido por uno originario que no es vivenciado por mí y que empero está ahí, se manifiesta, en mi vivenciar no originario (Stein, 2004, pp. 24-27).

Esta es, entonces, la peculiaridad fundamental de los actos de impatía: que el yo que realiza la impatía no es el mismo yo impatizado; es diferente de mi yo actuante, porque precisamente en dicho acto se revela otro ser que no soy yo.

De esta manera, hemos resaltado los actos presentificantes en su más pura generalidad; pretendemos describir cómo se experimenta la conciencia extraña en general. El discurso se ha afanado por poner en evidencia al yo puro, al sujeto del vivenciar. Y así entonces se da la experiencia que un yo, o una subjetividad en general, tiene de otra subjetividad en general; es decir, es la forma como el yo aprehende la vida anímica del otro ${ }^{6}$.

Antes de pasar a la impatía como experiencia de los individuos psicofísicos y sus vivencias, es decir, como cuerpos, precisemos algunos aspectos que hemos resaltado con respecto al problema impático.

6 Dice Stein (2004): “Pero así aprehende también (...) /el ser /creyente, el amor, la cólera, el mandamiento de su Dios" (pp. 24-27). 


\section{Recapitulación al problema de la impatía}

La impatía, entonces, es un acto por el cual una subjetividad humana, por lo regular sensitiva y racional, participa de una situación que es ajena a dicha subjetividad. Ese mundo extraño pertenece a una subjetividad que, como tal, tiene también sus libertades y sus proyectos, pero en la cual, efectivamente, el sujeto identifica que no es él mismo, por el reconocimiento de su esfera de propiedad (eingenheitssphäre). A la esencia de este acto, como se ha expresado, le es inherente una duplicidad: un vivenciar propio en el que se manifiesta otro vivenciar.

Ahora bien, para hacer comprensible este acto en que un ego constituye a otro, encontramos dos especies de procesos: en uno, un sujeto expande o prolonga su propio ser hacia otra realidad como si, saliendo de su esfera, invadiera una esfera extraña; esta proyección tiene la forma de revelarnos la situación de un yo que no soy yo. El otro proceso significa que dicho sujeto parece asir ciertos modos de la situación de ese ser otro que no soy yo. En rigor, este acto se hace posible por una apercepción analógica a la que luego haremos referencia.

Diríamos en general que el concepto rigurosamente definido de impatía se refiere a la experiencia de la conciencia extraña, en donde aprehendemos cognitivamente el dolor o cualquier padecimiento del otro, y hemos aclarado, en definitiva, que cuando hacemos referencia a la impatía damos por entendido que se trata de una vivencia no originaria que pone ante los ojos una vivencia originaria. Su modo de darse, al igual que los otros actos de conciencia que hemos referido, es por presentificación. En definitiva, por contraposición a las vivencias propias percibidas en las cuales se nos revela un yo propio, tenemos una experiencia impática que nos revela un individuo extraño o ajeno.

Hasta ahora, entonces, para hacer comprensible el fenómeno de la impatía, hemos tratado de explicitar lo que aquella experiencia significa desligada de todas las contingencias del aparecer. $Y$ nos hemos referido a ella como vivencia o conciencia puramente dada, sin poner en evidencia el tipo de sujeto al que se refiere, ni la experiencia propia del individuo psicofísico. 
Entonces, luego de haber explicitado el eidos, la esencia de la experiencia impática, es decir, haciendo fenomenología estática o eidética, vamos a referirnos, a continuación, al ámbito genético de dicha experiencia; en otros términos, luego de haber aprehendido el fenómeno en su esencia pura, el darse innegable de la vivencia extraña, vamos a mirar el cómo de esa experiencia. Al describirla en su origen nos adentramos desde el análisis estático hacia un nuevo análisis de orden genético, al cual nos referiremos más adelante.

Por ahora, tratemos de comprender el ámbito de la impatía como un problema de constitución fenomenológica. Con ello intentamos responder a la pregunta de cómo se constituyen en la conciencia las diversas objetividades (individuo psicofísico, persona espíritual). La constitución que más nos interesa en el presente texto es la del individuo psicofísico en el que se da el cuerpo vivo. Ello con el fin de entrar a delimitar el campo de la corporalidad, pues es el cuerpo el que define, en últimas, las relaciones concretas con el otro. Haremos un estudio preliminar acerca de cómo se nos revela el cuerpo vivo.

\section{La revelación del cuerpo vivo extraño y sus características}

El tratamiento de la constitución del individuo precisa hacer el tránsito desde el ámbito psíquico a lo psicofísico. Siendo que la única posibilidad de existencia de lo psíquico se da necesariamente en un cuerpo vivo, nos damos cuenta de que toda separación es artificiosa. Efectivamente, el ser de la conciencia es plenamente conciencia y cuerpo, o, íntegramente, cuerpo y conciencia. Entonces nos vemos precisados a hacer referencia al problema de la corporeidad.

Todas las cosas del mundo están encausadas hacia el cuerpo y lo revelan. Las cosas que el hombre usa son cuerpos y son usadas por él en tanto tiene naturaleza corpórea. Los cuerpos están en todas partes ocupando lugares en el espacio. Todos los lugares presuponen los cuerpos, ya que los cuerpos son cosas útiles que se aprehenden usándolas. Son cosas útiles dadas a los sujetos y, en general, a todos los seres sensibles. Yo tengo presencia corpórea, soy necesariamente cuerpo en todos los lugares y espacios de la sociedad y del mundo. 
Es de suma claridad que el mundo en el que vivo no es solamente un mundo de cuerpos físicos; además de mí, también hay en él sujetos con vivencias. Al cuerpo del otro hay que sacarlo de la gran familia de los cuerpos y ponerlo como un ser humano corpóreo situado en el mundo. El cuerpo del otro, salvo imaginariamente, o tratado sectorialmente por el cirujano, o en objetivación extrema y patológica, no se exhibe meramente como cuerpo físico (Körper), localizado espacialmente, sino como cuerpo que tiene su centro de orientación desde dentro de sí mismo, es decir, un cuerpo vivo sentiente (Leib), al que pertenece un yo individual que paradójicamente vive y padece el mundo.

De esta manera, hay un individuo, un ser unitario en el que se encuentran inseparablemente unidos la conciencia de un yo que brinda unidad y un cuerpo físico que refleja vida:"El cuerpo aparece como cuerpo vivo; la conciencia como alma del individuo unitario. La unidad se atestigua en que ciertos procesos se dan como pertenecientes al alma y al cuerpo vivo a la vez (sensaciones, sentimientos comunes)" (Stein, 2004, p. 75) 7 . Este cuerpo vivo está caracterizado frente al cuerpo físico, dado en actos de percepción externa, por varias características que es necesario poner de relieve: es portador de campos de sensación, es el punto cero de orientación en el espacio, tiene capacidad de movimiento libre y es campo de expresión de las vivencias del yo (pp. 75-103).

El cuerpo vivo extraño se caracteriza frente al cuerpo físico porque es portador de campos de sensación. Ahora bien, ¿cómo se nos dan los campos de sensación? De los campos propios de sensación decimos que en toda percepción de los cuerpos hay un darse originario, y sabemos que las vivencias originarias son todas aquellas vivencias propias presentes. Nosotros percibimos de modo inconsciente la totalidad del objeto; pero concomitante con la cosa espacial, en mi propio campo de sensación, se revelan igualmente los lados ocultos del objeto. Entonces, en tanto que lo visto se presenta por perfiles o escorzos (Husserl, 1986, p. 91 ss.), aparece al tiempo como todo visto, pues junto a los horizontes externos que son codados, están los horizontes internos que, aunque no sean captados de modo originario, se presentan imaginaria

$7 \quad$ Este tema es tratado de forma exhaustiva por Husserl (1997), en el apartado III de la Sección Segunda de Ideas II: "La constitución de la realidad anímica a través del cuerpo", §§ 35-41, pp. 183 ss. 
e inconscientemente como la totalidad vista con base en experiencias del pasado; por ejemplo, cuando entramos en nuestro cuarto y hacemos la reducción, éste se presenta a la percepción inmediata por perfiles y yo, con lo imaginario, de modo inmediato e inconsciente, construyo los lados no vistos, pero con él están igualmente covistos los lados externos.

Con respecto a los campos de sensación del otro para mí, tenemos que el cuerpo del otro es constituido como cuerpo vivo, pero ya no en un darse como "cumplimiento originario" ni en "percepción progresiva externa" (Stein, 2004 , p. 76), sino por medio de una presentificación impatizante. De esta manera, la intuición pertinente no tiene la forma de la percepción, sino de la presentificación; por ejemplo, igual que capto mis pies al lado de otros cuerpos, los diferencio de los objetos del mundo como cuerpo vivo propio, y los pies del otro igual los capto, no en el modo de la originariedad, sino al modo de la impatía en el que me transfiero dentro de lo otro: se percibe el cuerpo ajeno como miembro de un cuerpo vivo propio. Entonces, las sensaciones impatizadas por contraposición a las propias se revelan constantemente como extrañas (pp. 75-78).

Una característica importante que resalta la autora refiriéndose, por ejemplo, a las sensaciones de placer, de calor y otras sensaciones, es que son tan absolutamente dadas como los actos de juicio, de percepción, etc., pero se diferencian de éstos en tanto no brotan del yo puro, del cogito, y en consecuencia no se revela ningún yo en ellos, sino que se revelan localizados en el espacio, es decir, cercanos al yo pero de ningún modo originados en el yo, como sí sucede, por ejemplo, con los actos de voluntad y percepción (Stein, 2004, p. 60).

Otro ámbito que caracteriza al cuerpo vivo se refiere al hecho de ser punto cero de orientación del mundo espacial. El cuerpo del otro como cuerpo físico está dado como una cosa que ocupa un lugar en el espacio. Se presenta a mi mirada como exterioridad pura al lado de otras cosas del mundo, y así, se aparece a cierta distancia de mí que, mientras se revela a mi mirada como objeto, es, en tanto lo mantenga como tal, parte de un entorno que se organiza alrededor de mí, ya que soy el punto cero (Nullkpunt) de orientación en el cual yace él, en concomitancia con el mundo espacial en el que está inmerso (pp. 80-84). 
Así, en tanto lo aprehendo como un cuerpo vivo sensible, me ensimismo en él (o me transfiero en él) impatizando. Con dicho acto se revela ante mí un nuevo centro de orientación de un ser que ya no forma parte de la gran familia de los cuerpos, en tanto es un cuerpo vivo en el mundo que igual se muestra como un ser que pone un entorno a su alrededor. Pero esto se hace posible dado que, en mi comprensión de él, sé que puede recuperar su subjetividad para volverse contra mí, como si yo fuese un objeto, haciéndome perder mi subjetividad y, en últimas, haciéndome perderme a mí mismo como en actitud natural ${ }^{8}$. No se trata entonces únicamente de un sujeto que tiene sensaciones, sino de un sujeto situado en el mundo, que realiza actos voluntarios; por ejemplo, el acto de impatizar como mutua posibilidad del ego y del extraño.

Así, el cuerpo del otro, como cuerpo físico, es una cosa espacial al lado de otras en el espacio, a cierta distancia de mí y como centro de orientación espacial. En la medida en que lo comprendo como cuerpo vivo sensible me transfiero a él impatizando y se me revela otro punto nuevo de orientación que es el suyo, sin que ello signifique que yo me desplace desde mi punto de orientación hacia el del otro, sino que, conservando mi punto cero de orientación que es originario, me transfiero hacia el de él en la forma de presentificación que es a la vez originaria para el otro yo.

Entonces, con el punto cero de orientación del otro que se obtiene con la impatía, puedo comprender (u observar fenomenológicamente) que mi punto de orientación no es ya un punto cero, en tanto que es un punto espacial entre muchos, y por ello aprendo a ver mi cuerpo vivo como un cuerpo físico como los demás. Esto tiene consecuencias fundamentales para el tema de la intersubjetividad y la constitución de la subjetivividad personal que Husserl desarrolla ya desde Ideen II. Stein termina esta interesante reflexión sobre el cuerpo vivo como centro de orientación haciendo referencia a que la posibilidad de desplazarme física o fantásticamente de mi centro de orientación

8 Este tema, como se habrá notado, ha sido trabajado magistralmente por Sartre en la tercera parte de El ser y la nada (1976, p. 328 ss.) y tiene como consecuencia para su filosofía el hecho de poner las relaciones entre el otro y yo, esencialmente, como relaciones de conflicto, y establecer una fenomenología de la mirada. No podemos ocuparnos de ello en el presente texto. Solamente queremos resaltar, de la mano de Edith Stein, el notorio avance frente a la constitución de los campos de sensación. Para un estudio del tema de la mirada tal y como la propone el fenomenólogo francés, ver Aristizábal Hoyos (2005). 
la hace posible la impatía, pero no es posible establecer una observación sobre mí como sí podría hacerlo sobre cualquier cuerpo físico. La autora ilustra esta idea de la siguiente manera: "Cuando yo me diviso en la copa de un árbol en un recuerdo de infancia o fantaseando, a la orilla del Bósforo, entonces me veo como otro, o como otro me ve. Y esto me lo posibilita la /i/mpatía" (Stein, 2004, p. 82). Esto descubre otra instancia de mi ser que es la objetividad, la cual revela la exterioridad de mi cuerpo.

Respecto al cuerpo vivo como ser con capacidad de movimiento libre, nos damos cuenta de que los movimientos del otro los percibimos a la vez como movimiento vivo y mecánico, e igual pasa cuando mi cuerpo es mirado por otro. Por ejemplo, si con un pie sostengo otro pie y lo muevo de un lado a otro, el pie que sostiene aparece como movimiento mecánico, como ocurriría con cualquier objeto que mecánicamente muevo de un lado al otro.

Así, el movimiento propio visto desde el exterior es meramente mecánico, igual que el movimiento propio de un ser vivo, y ambos movimientos se captan como el mismo movimiento. Stein lo ilustra con el siguiente ejemplo:

Si veo a alguien pasar en un carruaje, su movimiento no me parece en principio distinto al de las partes -fijas- del carruaje: es (...) /movimiento compartido/ mecánico que yo percibo, no /i/mpatizo- externamente. (...)/Pero cuando/ se pone en pié en el carruaje yo veo un movimiento del tipo de mi movimiento propio y lo comprendo como movimiento propio (...), a la manera de la impatía (p. 86).

Entonces, al cuerpo del otro como cuerpo vivo, sea que se mueva o esté quieto en relativa rigidez, le es inherente el movimiento, o la capacidad potencial de hacerlo. De esta manera, aprehender "el movimiento propio de un cuerpo físico como movimiento vivo" (p. 86) presupone impatizar en el movimiento vivo del otro. Y por eso es preciso comprender que el cuerpo vivo extraño se da en su libre movilidad, y a su estructura pertenece el libre movimiento animado a partir de sus órganos móviles.

Por último, el cuerpo vivo extraño es portador de los fenómenos de expresión de vivencias y sentimientos del yo. Así, en tanto que experimentamos senti- 
mientos, éstos terminan en expresión. El sentimiento, como vivencia del yo, tiene la característica de no ser algo cerrado en sí, sino que está abierto al mundo en tanto su carga de energía necesita de alguna manera soltarse y liberarse como carga de energía. Y esta descarga se presenta entonces motivando actos de voluntad y acciones que son inherentes a su liberación. Igual, dice Stein, el movimiento que genera un acto de voluntad tiene que generar un fenómeno expresivo que se expresa en múltiples formas (violencia, amor, fantasías de acción frente a una situación reprimida, actos de reflexión, etc.); así se comprende que existe una conexión esencial y de sentido entre sentimiento y expresión (pp. 69-72).

La expresión es, entonces, una función que, erróneamente o no, posibilita aprehender, en sí misma, la vivencia expresada. No obstante, la comprensión de esa vivencia no es originaria sino presentificada, o mejor aún, impatizada. Por tanto, la aprehensión del cuerpo vivo del otro, comprendido como cuerpo vivo de un yo, posibilita constituir la comprensión de la expresión corporal.

Uno de los aspectos que interesa señalar en este último punto sobre el cuerpo vivo como portador de los fenómenos de expresión, es que la expresión es un fenómeno que difiere sustancialmente de los de la sensación del otro inherentes a su estrato sensible, pues la sensación me viene dada como un dato sensible. Aprehendo lo anímico con lo corporal; en cambio, en la expresión está lo anímico no solamente percibido con lo corporal, sino expresado a través de lo corporal (p. 94). Esto se da, por ejemplo, con un fenómeno como la vergüenza: si estoy realizando desprevenidamente y en soledad unos gestos horribles y vulgares que precedieron a una emoción cualquiera, en principio esos actos no son censurados por mí sino que yo soy esos gestos; pero depronto escucho ruidos a unos metros de mí, yo siento o imagino que alguien me mira, y ese alguien me hace descubrirme a mí mismo como vulnerable y me revela, por ejemplo, una instancia objetiva de mi vida. Ese fenómeno de expresión corporal, entonces, revela un rasgo psíquico, y al transferirse dentro del cuerpo vivo extraño impatizando, se posibilita entonces comprender mejor ese vivenciar. Pero ese vivenciar, como hay que entender, no es originario sino presentificado en la forma específica en que nos hemos ocupado en este texto, es decir, impatizando. 
En resumen, en este último aspecto, nos hemos visto en la necesidad de hacer el tránsito desde lo puramente psíquico, que nos permitió conocer la esencia de la impatía, hacia lo psicofísico que nos permitió referirnos al cuerpo, en la medida en que lo psíquico se manifiesta necesariamente como cuerpo vivo. Hemos explicitado igualmente algunas características del cuerpo vivo con el fin de mostrar cómo se da el fenómeno de la impatía en el mundo de lo psicofísico y de la corporeidad, e igualmente intentando determinar un primer acercamiento a la constitución fenomenológica del cuerpo vivo extraño.

El haber explicitado el fenómeno de la impatía en su aspecto psíquico y psicofísico nos ha permitido abrir una ventana sólida de acercamiento a la fenomenología de la intersubjetividad, ya que acercarnos al tema de la impatía es entrar a indagar el problema central de las relaciones entre el otro y yo.

Toda fenomenología de la intersubjetividad se comprende exhaustivamente a través de la llamada "reducción intersubjetiva", y una explicación completa de dicha reducción requeriría indagar el tema de las modalidades de la ventana monádica (idealista, social y pre-reflexiva) con la que Husserl soluciona, a nuestro modo de ver, el problema del solipsismo, en tanto que muestra una efectiva comunicación entre las mónadas; no obstante, este es tema de otro estudio.

\section{Referencias}

Aristizábal Hoyos, P. J. (2005). Subjetividad, historia y cultura. Estudios fenomenológicos. Bogotá: Alejandría Libros.

Brentano, F. (1935). Psicología desde el punto de vista empírico. Madrid: Revista de Occidente.

Embree, L. (2003). Análisis reflexivo. Una primera introducción a la investigación fenomenológica. México: Jitanjäfora Morelia Editorial. Red Utopía, A. C.

Fink, E. (2003).“La filosofía fenomenológica de Husserl ante la crítica contemporánea". En Acta fenomenológica latinoamericana (vol. I). Lima: Pontificia Universidad Católica del Perú. 
Husserl, E. (1995). Investigaciones Lógicas II. Madrid: Alianza Editorial.

Husserl, E. (1973a). Zür Phänomenologie der intersubjetivität (Husserliana XIII). Den Hagg: Martinus Nijhoff.

Husserl, E. (1973b). Zur Phänomenologie der Intersubjektivität (Husserliana XV. Den Hagg: Martinus Nijhoff.

Husserl, E. (1986a). Cartesianische Meditationes und Pariser Vorträge (Husserliana I). Den Hagg: Martinus Nijhoff.

Husserl, E. (1986b). Ideas relativas a una fenomenología pura y a una filosofía fenomenológica. México: F.C.E.

Husserl, E. (1987). Erste philosophie II. Kritische Ideen Gestichichte. Den Hagg: Martinus Nijhoff.

Husserl, E. (1997). Ideas relativas a una fenomenología pura y a una filosofía fenomenológica. Investigaciones fenomenológicas sobre la constitución. México: UNAM.

Husserl, E. (1991). La crisis de las ciencias europeas y la fenomenología trascendental. Barcelona: Crítica.

Iribarne, J. (1988). La intersubjetividad en Husserl. Bosquejo de una teoría (Tomo II). Buenos Aires: Ediciones Carlos Lohlé.

Iribarne, J. (2005). "Temporalización - Mónada". En: Acta fenomenológica latinoamericana (vol. II). Lima- Bogotá: Pontificia Universidad Católica del Perú - San Pablo.

Márquez, C. M. (1987). “El espíritu común” (I y II Manuscrito AV 23, nota 1b). Thémata, (4), 131-158.

Sartre, J. P. (1976). El sery la nada. Ensayo de ontología fenomenológica. Buenos Aires: Losada.

Stein, E. (2004). El problema de la empatía. Madrid: Trotta.

Zirión Quijano, A. Glosario-guía para traducir a Husserl. Recuperado el 31 de enero de 2010 desde http://www.ggthusserl.org/ggth/default.html 